\title{
Corporate Brand Impact on Sales / Revenue Per Share
}

By

Brad A. Puckey, University of South Florida

T his research project is designed to an swer the question, what is the corporate brand's impact on sales / revenue per share generation. For decades, the impact of corporate brand on share price and product brand on revenue generation has been fairly well understood. The impact of corporate brand on sales / revenue generation has been widely assumed, but not proven.

This topic is important as companies allocate more and more resources to communicating their brands and need to determine return and accountability for these expenditures. It is not enough to simply assume that there will be an impact on business results anymore, linkages must be identified and quantified.

Traditional brand valuation approaches identified a single methodology or unit of measure and argued that they were the best and only method of valuing a brand. This research builds on the theory of intangible capital, which states that brands create value for companies through many avenues and channels. As many of these as can be identified will peel back the various layers and more fully explain the picture of intangible capital and brand value. This is the key to helping brand communications executives

Keywords: Branding, Quantitative, CHAID, Branding Value, Branding Output

Copyright $\odot 2021$ Brad A. Puckey. This article is published under a Creative Commons BY-NC license. Permission is granted to copy and distribute this article for non-commercial purposes, in both printed and electronic formats 
The motivation for this research was to fill a gap that existed in the knowledge of brand valuation and intangible capital. It is intended to give those with accountability for the brand additional information to aid their decision making and asset allocation. The research question is, "what is the corporate brand's impact on sales / revenue per share generation?" The hypotheses explored are:

H1: Growth in BrandPower will result in growth in sales-/revenue-per-share change.

$\mathrm{H} 2$ : Change in Familiarity and Favorability will have different, but positive, impacts on sales/revenue-per-share growth.

H3: The different attributes that make up Favorability have a different, but positive, impact on

sales/revenue-per-share.

H4: Various conditions, such as industry affiliation, will positively alter the impact of brand factors on sales/revenue-per-share growth.

A total of 617 companies from the CoreBrand In$\operatorname{dex}^{\oplus}$ met the criteria of continual tracking from 2011 - 2016. These companies span 52 industries in 11 sectors and presented the opportunity for both macro and micro modeling.

In the data exploration phase, correlation and quintile analyses indicated that a time horizon of 5-years represented the best opportunity to build a strong model. Over that period the average sales/revenue per share growth rate was $20.6 \%$. The Chi Squared Automatic Interaction Detector, or CHAID, methodology was chosen for this analysis, as it is not impacted by issues such as multicollinearity and is also adept at working with missing values in the dataset. The objective of the model is to accurately predict of a company will be high or low sales / revenue per share, above or below 20.6\%. A series of CHAID models were constructed to model macro performance, and performance in 3 key sectors: consumer, industrials and technology. These sectors were chosen for having very different products and customer bases to determine if there are differences in performance based on company type.

\section{Findings}

The models each identified key performance drivers identified based on the quantitative brand data, industry affiliation and financial fundamental data. In each case, the model accurately predicted high or low sales / revenue per share growth rates in over $80 \%$ of the cases. The models also identified a vast set of differences in the predictors of performance.

The macro model identified 6 drivers of performance; this was the most of all the models. It is not surprising because this model utilized the most data. The consumer model identified 2 drivers, also not surprising because this is probably the least complex market. The other 2 models identified 4 drivers each. Each identified different drivers telling us how those markets are different and identifying different concerns for each. In each case, corporate brand factors were identified as important drivers of performance. The model also identified that industry affiliation was a major factor driving performance, which necessitates different approaches to communications. This is important for communications executives responsible for developing messaging and allocating resources to communications efforts.

The limitations of this research are that it only loos at 5 -year change in a single time period. Additional time periods should be examined to validate the results and provide additional rigor. Also, product brand data was not available and should be used to separate the effects of product brand from corporate brand.

\section{Conclusions}

This research demonstrated that the corporate brand plays a significant role in driving a company's sales / revenue per share growth. It also demonstrates that these effects are understandable and predictable and, while this is still considered intangible capital, it can be measured and managed for value creation.

These models demonstrated that the various markets have differing degrees of complexity and different drivers of value creation. This provides different consideration for communications executives and various communications objectives in individual markets.

These findings have implications not only for communications executives but also for venture capitalists and other potential lending organizations. By understanding the strength and performance of the corporate brand, the chance to evaluate a company's chances for success are improved.

\section{References}

Gregory, J. R. (2018). Intangible capital: Culture of innovation and its impact on the cash flow multiple [Doctoral dissertation, University of South Florida]. Scholar Commons.

Puckey, B. (2012). Brand revenue: Measuring the brand's ability to impact revenue. Association of National Advisors. http://www.ana.net/miccontent/show/id/ib-brand-revenue-corebrand

\section{Review}

This article was accepted under the constructive peer review option. For futher details, see the descriptions at:

http://mumabusinessreview.org/peer-review-options/ 


\section{Authors}

Brad A. Puckey graduated from USF with his doctorate in business administra-
tion in 2020. He went to Indiana University of Pennsylvania and earned a Bach-
elor of Arts in Economics, where he was involved in student government and
a member of the Pi Kappa Phi fraternity. Prior to attending college, Brad was a
member of the United States Army, where he served as an Electronic Warfare
Signals Intelligence (SIGINT) Analyst. He served tours at the National Securi-
ty Agency at Ft. Meade, MD; A Company, Military Intelligence Battalion (Low
Intensity) Soto Cano Airbase, Honduras; and 1st Infantry Division (the Big Red
One) at Ft. Riley, KS.

